\section{Effect of Diet Supplemented with Rumen- protected 5-Hydroxytryptophan on the Concentration of 5-Hydroxytryptophan and Melatonin in the Plasma of Sheep}

\author{
Fang Zhao, Gen Wang, Xiaobin Li, Guodong Zhao, Hui Chen, Chen Ma and \\ Kailun Yang*
}

Xinjiang Key Laboratory of Meat and Milk Production Herbivore Nutrition, Xinjiang Agricultural University, No. 311, Nongda East Road, Shayibake District, Urumqi 830052, China

\begin{abstract}
A B S T R A C T
This study was conducted to investigate the effect of diet supplemented with rumen-protected 5-hydroxytryptophan (RPT 5-HTP) on the concentration of 5-hydroxytryptophan (5-HTP) and melatonin (MLT) in the plasma of sheep. Eighteen sheep were assigned randomly to three diet groups $(n=6)$. The treatment groups included control (CT, corn-soybean meal basal diet), CT $+111(\mathrm{CT}+111 \mathrm{mg} / \mathrm{kg} \mathrm{BW}$ RPT 5-HTP), and CT $+222(\mathrm{CT}+222 \mathrm{mg} / \mathrm{kg} \mathrm{BW}$ RPT 5-HTP) groups. The experiment lasted for $16 \mathrm{~d}$. On the 16th day of the experiment, blood samples from the sheep were collected at $0 \mathrm{~h}$ before feeding and at $1.5,3,4.5,6,8,10$, and $12 \mathrm{~h}$ after feeding in the morning. The plasma concentration of 5-HTP, tryptophan (Trp), 5-hydroxytryptamine (5-HT), and MLT was determined. The plasma concentration of 5-HTP at 6,8 , and $10 \mathrm{~h}$ after feeding in the morning increased $(P<0.05)$ in response to RPT 5-HTP supplementation when compared with that at $0 \mathrm{~h}$ before feeding. The plasma concentration of Trp remained unchanged with RPT 5-HTP supplementation. However, the plasma concentration of 5-HT increased significantly in the sheep of $\mathrm{CT}+222$ group at $3,4.5,6,8$, and $12 \mathrm{~h}$ post feeding in the morning when compared with that at $0 \mathrm{~h}$ before feeding. The effect of RPT 5-HTP supplementation on the plasma MLT concentration was observed. The concentration of MLT increased $(P<0.05)$ from 1.5 to 6 $\mathrm{h}$ after feeding. In conclusion, RPT 5-HTP supplementation increased the plasma 5-HTP, 5-HT, and MLT concentrations in the sheep. However, the plasma Trp concentration in the sheep remained unchanged after RPT 5-HTP supplementation.
\end{abstract}

\begin{tabular}{l} 
Article Information \\
\hline Received 17 July 2018 \\
Revised 22 March 2020 \\
Accepted 26 September 2020 \\
Available online 31 May 2021 \\
(early access) \\
Published 22 January 2022 \\
Authors' Contribution \\
\hline ZF and YKL conceived and designed \\
the experiments, ZF, WG, LXB and \\
ZGD performed the experiments. \\
ZF and CH analyzed the data. MC \\
contributed reagents/materials/ \\
analysis tools. \\
Key words \\
Rumen-protected \\
5-hydroxytryptophan, Sheep, Plasma, \\
5-hydroxy- tryptamine, Melatonin
\end{tabular}

\section{INTRODUCTION}

$\mathrm{M}$ elatonin (MLT), a circadian rhythm regulatory hormone (Arendt, 1998), controls the expression of clock genes at the central and peripheral tissue levels in organisms (Alonso-Vale et al., 2008; de Farias Tda et al., 2015; Vriend and Reiter, 2015). Melatonin regulates several physiological functions related to circadian alterations (Dijk and Cajochen, 1997; Miller et al., 2006; Pandi-Perumal et al., 2005; Zhdanova, 2005). It is a potent free radical scavenger and antioxidant (Reiter et al., 2016). It not only directly interacts with reactive oxygen species (ROS) and reactive nitrogen species (RNS), but also upregulates the activities of antioxidant enzymes (Ding et al., 2014; Galano et al., 2011, 2013; Manchester et al., 2015). Furthermore, MLT $\left(10^{-7} \mathrm{~mol} / \mathrm{L}\right)$ exhibited potent

\footnotetext{
* Corresponding author: 490735574@qq.com 0030-9923/2022/0002-0777 \$9.00/0

Copyright 2022 Zoological Society of Pakistan
}

effects on porcine oocyte maturation under heat stress (Li et al., 2016). MLT also promotes bovine embryonic development under both in vitro and in vivo conditions (Wang et al., 2014). In addition, MLT advances the onset of estrus in adult ewe (English et al., 1986). Overall, MLT is secreted by the pineal gland mainly during dark period, and the changing circadian pattern of MLT secretion mediates the effect of changing photoperiod (day length) on various physiological functions in several species.

Based on the extensive biological effects of MLT, appropriately increasing the MLT content in animals might be of significance. Increased intake of MLT precursor material through diet can increase the MLT content in animal blood. Tryptophan (Trp) increases the plasma MLT level in monogastric animals, such as chicken, rat (Huether et al., 1992), and mice (Sanchez et al., 2004). In contrast, Trp supplementation in sheep is not an effective approach to increase blood 5-hydroxytryptamine (5-HT) or MLT synthesis (Sugden, 1989). In sheep, there was an interspecific difference in Trp-induced increase in the plasma 
MLT concentration. However, L-5-hydroxytryptophan (5HTP, $200 \mathrm{mg} / \mathrm{kg}$ BW i.p.), but not Trp $(500 \mathrm{mg} / \mathrm{kg}$ BW i.p.), supplementation substantially increased the serum MLT concentration in sheep (Sugden et al., 1985). The serum MLT concentration was elevated at $2-5 \mathrm{~h}$ after the injection of 20 or $200 \mathrm{mg} / \mathrm{kg} \mathrm{BW}$ in sheep (Namboodiri et al., 1983).

5-HTP is synthesized from Trp by the action of Trp hydroxylase. Tryptophan hydroxylase transfers a hydroxyl group to the C5 position of the indole ring to give 5-HTP. Aromatic amino acid decarboxylase removes the side-chain carboxyl group to give 5-HT. MLT is synthesized from serotonin in a two-step process by the sequential action of pivotal enzymes, aralkylamine $N$-acetyltransferase (AANAT) and hydroxylindol-O-methyl transferase (Maronde and Stehle, 2007).

Therefore, in the present study, we hypothesized that the RPT 5-HTP can elevate the plasma 5-HT concentration, and thus, will affect the synthesis of MLT in sheep during daytime. The effects of RPT 5-HTP supplementation on the concentration of Trp and 5-HTP, which are the two major precursors of MLT synthesis, were observed.

\section{MATERIALS AND METHODS}

L-5-Hydroxytryptophan was purchased from Wuhan Yuancheng Gongchuang Technology Co. Ltd. (Wuhan, China). Additionally, RPT L-5-HTP (containing 45\% L-5HTP) was procured from Beijing Yahe Products Co. Ltd. (Beijing, China).

\section{Animals and design}

This study was conducted using 3-yr-old Kazakh sheep (female) with an average body weight of 47.79 $\pm 3.70 \mathrm{~kg}$ in the Xinjiang Huikang Animal Husbandry Biotechnology Co. Ltd.

Eighteen sheep were randomly assigned to three diet groups $(\mathrm{n}=6)$. The treatments groups included CT (control group, corn-soybean meal basal diet), CT +111 (CT $+111 \mathrm{mg} / \mathrm{kg}$ BW RPT 5-HTP), and CT +222 groups $(\mathrm{CT}+111 \mathrm{mg} / \mathrm{kg}$ BW RPT 5-HTP); 5-HTP content in CT +222 was two times higher than that in CT +111 . The experimental period lasted for $16 \mathrm{~d}$. Rumen-protected L-5-hydroxytryptophan was added to the concentrate diet. The levels of RPT 5-HTP were chosen according to the study of Sugden et al. (1985). Based on the differences in weight and breed, we set two levels of supplementation 111 and $222 \mathrm{mg} / \mathrm{kg} \mathrm{BW}$ RPT 5-HTP. On the $16^{\text {th }}$ day of the experiment, blood samples were drawn from the external jugular vein during daytime, at $0 \mathrm{~h}$ before feeding and at $1.5,3,4.5,6,8,10$, and $12 \mathrm{~h}$ after feeding. The samples were then centrifuged at $120 \times g$ for $10 \mathrm{~min}$ to obtain the plasma for 5-HTP, Trp, 5-HT, and MLT assays. The animal care, handing, and sampling procedures were carried out in strict accordance with the protocol approved by the Xinjiang Agricultural University Animal Care and Use Committee.

\section{Diets and feeding}

The sheep were housed in an open-sided barn in individual pens $(1.0 \mathrm{~m} \times 1.5 \mathrm{~m})$. The powder concentrate was fed at a concentration of $1.0 \%$ of the body weight daily and divided into two equal meals at 07:30 and 19:30 h. Hay and fresh water were provided ad libitum. The formulation and nutrition composition of powder concentrate and the nutrition composition of hay are presented in Tables I and II.

Table I. Formulation and nutrition composition of powder concentrate (dry matter basis).

\begin{tabular}{|c|c|c|c|}
\hline \multicolumn{2}{|c|}{ Powder concentrate } & \multicolumn{2}{|c|}{ Nutrient composition } \\
\hline $\begin{array}{l}\text { Material } \\
\text { name }\end{array}$ & $\begin{array}{l}\text { Content } \\
(\%)\end{array}$ & $\begin{array}{l}\text { Nutrient } \\
\text { name }\end{array}$ & $\begin{array}{l}\text { Content } \\
(\%)\end{array}$ \\
\hline Corn & 44 & $\mathrm{DM}$ & 91.28 \\
\hline Soybean meal & 20 & $\mathrm{OM}$ & 84.29 \\
\hline Oat & 16 & $\mathrm{CP}$ & 21.82 \\
\hline Barley & 15 & NDF & 36.24 \\
\hline $\mathrm{CaHPO}_{4}$ & 3 & $\mathrm{ADF}$ & 12.97 \\
\hline Salt & 1 & $\mathrm{Ca}$ & 1.54 \\
\hline Premix & 1 & $\mathrm{P}$ & 0.59 \\
\hline Total & 100 & & \\
\hline
\end{tabular}

$\mathrm{ADF}$, acid detergent fiber; $\mathrm{Ca}$, calcium; $\mathrm{CP}$, crude protein; $\mathrm{DM}$, dry matter; NDF, neutral detergent fiber; $\mathrm{P}$, phosphorus

Table II. Nutrient composition of corn silage, alfalfa, and wheat straw (dry matter basis).

\begin{tabular}{llll}
\hline Items & Corn silage & Alfalfa & Wheat straw \\
\hline DM & 94.76 & 93.67 & 95.93 \\
OM & 84.05 & 85.30 & 82.49 \\
CP & 8.33 & 13.72 & 4.21 \\
NDF & 67.36 & 53.97 & 71.31 \\
ADF & 43.73 & 36.52 & 47.49 \\
Ash & 10.71 & 8.37 & 13.44 \\
Ca & 0.64 & 1.36 & 0.38 \\
P & 0.24 & 0.16 & 0.07 \\
For abbriviation, see Table I.
\end{tabular}

Sample analysis

The concentration of 5-HTP in the plasma was 
determined as described previously (Enbaek and Magnussen, 1978). The plasma (750 L) was mixed with $4 \mathrm{~mL}$ of acidified butanol (4 $\mathrm{mL}$ of $70 \% \mathrm{HClO}_{4}$ per liter of 1-butanol) and centrifuged $(1960 \times \mathrm{g}$ for 15 $\min$ at $4^{\circ} \mathrm{C}$ ). Subsequently, the precipitate was removed, the supernatant was mixed with $6 \mathrm{~mL}$ of n-hexane, and centrifuged $\left(5600 \times \mathrm{g}\right.$ for $20 \mathrm{~min}$ at $\left.4^{\circ} \mathrm{C}\right)$ to obtain 400 $\mu \mathrm{L}$ of aqueous phase (containing 5-HTP), which was used for column chromatography. The organic phase was discarded. Twenty-five microliters of the extracted plasma was applied to the column and the chromatogram was developed with the column buffer at $70^{\circ} \mathrm{C}$ with a flow rate of $0.3 \mathrm{~mL} / \mathrm{min}$. The effluent from the column was reacted with fluorogen reagent (per liter: $3 \mathrm{mmol}$ phthaldialdehyde, $20 \mathrm{mg} \mathrm{FC}-134$, and $150 \mathrm{mg}$ Brij 35, all in $9 \mathrm{~mol} / \mathrm{L} \mathrm{HCI}$. This reagent, prepared daily, was maintained in dark) at $70^{\circ} \mathrm{C}$ for $8 \mathrm{~min}$ before measuring the fluorescence.

The plasma Trp level was measured by fluorescence spectrophotometer (SHIMADZU, Japan). The plasma (50-100 $\mu \mathrm{L})$ was mixed with an equal volume of $0.6 \mathrm{~N}$ trichloroacetic acid and centrifuged at $2000 \times \mathrm{g}$ for $20 \mathrm{~min}$ at $4{ }^{\circ} \mathrm{C}$, the precipitate was removed, and the supernatant was diluted 5 times. One hundred microliters of the diluted plasma was dropped into a test tube, then added $0.9 \mathrm{~mL}$ distilled water, $2.5 \mathrm{~mL} 0.6 \mathrm{~mol} / \mathrm{L}$ trichloroacetic acid solution, $0.2 \mathrm{~mL} 2 \%$ formaldehyde solution and 0.1 $\mathrm{mL} 6 \mathrm{mmol} / \mathrm{L} \mathrm{FeCl3}-0.6 \mathrm{~N}$ TCA solution, respectively. Mixed the solution and placed a boiling water bath for $90 \mathrm{~min}$. The mixed solution was detected by fluorescence spectrophotometer (Excitation wavelength 304 micrometers, emission wavelength 448 micrometers).

The plasma 5-HT level was determined using an ELISA kit (Beckman-Coulter, Krefeld, Germany). The sample was diluted to $1: 100$ in order to ensure that it was within the range of the standard curve.

The plasma MLT concentration was measured using a commercial ELISA kit (IBL Hamburg, Germany). The detection limit was $3.0 \mathrm{pg} / \mathrm{mL}$, intra-assay-variation was $7.5 \%$, and inter-assay-variation was $11.3 \%$.

\section{Statistical analyses}

The data are presented as mean \pm standard deviation, and analyzed by repeated ANOVA test using the SPSS 18.0 statistical software (IBM, State of New York, Armonk USA). The results with $P$ value $<0.05$ were considered statistically significant and those with $P$ value $<0.01$ were considered significantly different.

\section{RESULTS}

\section{Plasma 5-HTP}

The supplementation of RPT 5-HTP increased the plasma 5-HTP level in the sheep of both at CT +111 and CT +222 groups (Fig. 1A). A significant increase was observed from $6 \mathrm{~h}$ up to $8 \mathrm{~h}$ post feeding in the morning $(P<0.05)$. In the control sheep, the 5-HTP concentration remained unchanged on all experimental days during daytime.

\section{Plasma Trp}

There were not differences in the plasma Trp content between the control, $\mathrm{CT}+111$, and $\mathrm{CT}+222$ groups (Fig. 1B). The plasma Trp content did not change significantly when compared with that of the control group after the administration of either $111 \mathrm{mg} / \mathrm{kg} \mathrm{BW}$ or $222 \mathrm{mg} / \mathrm{kg} \mathrm{BW}$ RPT 5-HTP $(P>0.05)$.
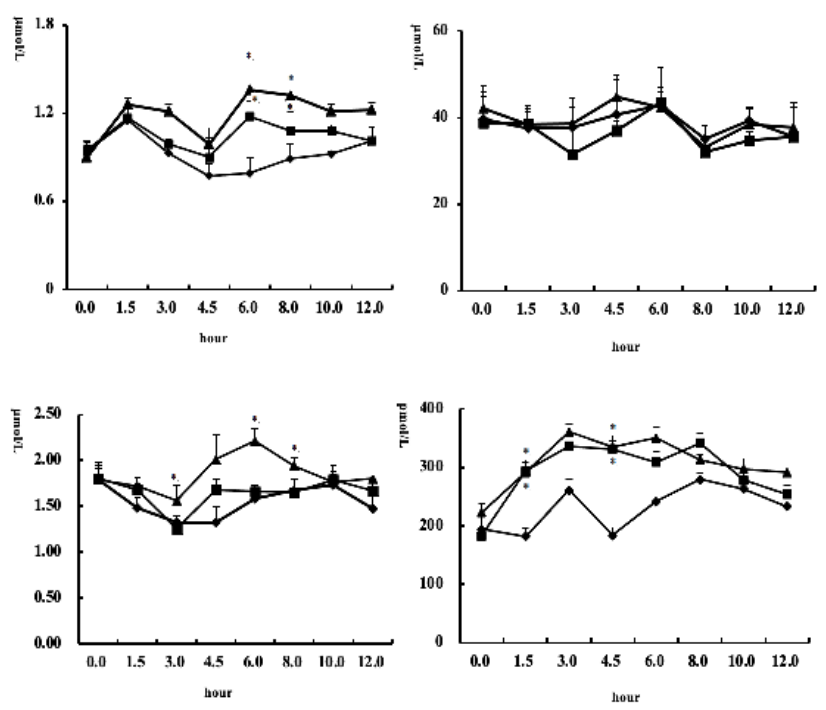

Fig. 1. Plasma 5-hydroxytryptophan (A) tryptophan (B) 5-hydroxytryptamine (C) and melatonin (D) concentrations in the sheep provided diet supplemented with $55.5 \mathrm{mg} / \mathrm{kg}$ BW RPT 5-HTP or $111 \mathrm{mg} / \mathrm{kg}$ BW RPT 5-HTP at 07:30 $\mathrm{h}$.

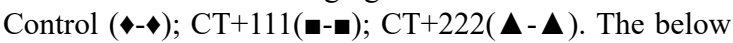
abscissa shows the time after feeding. The data are presented as mean \pm S.D. The means within a time point without common superscripts were significantly different $(P<0.05) .{ }^{*} P<0.05$.

\section{Plasma 5-HT}

In the control group, the concentration of 5-HT was low during $0-4.5 \mathrm{~h}$ post feeding, and then increased to a plateau that lasted the entire activity period (Fig. 1C). There was a significant difference in the level of 5-HT with time in the CT +222 group, with a maximum level at $6 \mathrm{~h}$ post feeding. Moreover, the plasma 5-HT content in the $\mathrm{CT}+222$ was significantly higher than that of the control at 3,6 , and $8 \mathrm{~h}$ post feeding in the morning $(P<0.05)$. However, there was no significant difference between the control and $\mathrm{CT}+111$ groups $(P>0.05)$. 


\section{Plasma MLT}

Because of the intake of diet at $07: 30 \mathrm{~h}$, the plasma MLT level increased during $1.5-3 \mathrm{~h}$ post feeding in the morning (Fig. 1D). The plasma MLT levels in the sheep of CT +111 and $\mathrm{CT}+222$ groups at 1.5 and $4.5 \mathrm{~h}$ post feeding were consistently higher than those in the sheep of the control group $(P<0.05)$. Furthermore, there was no significant difference in the plasma MLT level between the $\mathrm{CT}+111$ and $\mathrm{CT}+222$ groups $(P>0.05)$.

\section{DISCUSSION}

Fifteen days pretreatment with RPT 5-HTP (111 or $222 \mathrm{mg} / \mathrm{kg} \mathrm{BW}$ ), produced a significantly increase in the accumulation of plasma 5-HTP. The results of the present study are in accordance with those of Westenberg et al. (1982) and Joseph and Baker (1976), who demonstrated the changes in the serum 5-HTP level in humans after oral administration of 5-HTP. 5-Hydroxytryptophan is well absorbed from oral dose, with approximately 70 percent ending up in the bloodstream (Magnussen et al., 1981; Magnussen and Nielsen-Kudsk, 1980). The absorption of 5-HTP is not affected by the presence of other amino acids; therefore, it can be supplemented with diet in sheep. Unlike Trp, 5-HTP cannot be shunted into niacin or protein production (Birdsall, 1998).

There was no increasing trend of sheep plasma 5-HTP with the increased level of RPT 5-HTP. 5-Hydroxytryptophan is derived from Trp via a pathway in which Trp hydroxylase (TPH) catalyzes the rate limiting step in the synthesis of 5-HTP. Furthermore, TPH uses $\mathrm{Fe}^{2+}$ as a cofactor and $\mathrm{O}_{2}$ and tetrahydrobiopterin (BH4) as co-substrates to hydroxylate Trp generating 5-HTP (Mockus and Vrana, 1998). The major metabolic pathway of 5-HTP is decarboxylation to 5-HT. The concentration of L-aromatic amino acid decarboxylase is particularly high in the kidney, liver, and gut (Sourkes, 1987). Orally administered 5-HTP might therefore be metabolized in the gastrointestinal mucosa during absorption and by the liver before the amino acid reaches the systemic circulation (Magnussen et al., 1981). Our finding suggests that a part of administered 5-HTP is metabolized in the liver and gut before entering the bloodstream.

RPT 5-HTP treatment did not significantly change the plasma Trp concentration (Fig. 1B). The intestinal absorption of 5-HTP does not require transport molecules (Birdsall, 1998), whereas Trp is absorbed by amino acid transporters (Broer, 2008a, 2008b). This indicates that 5-HTP absorption is not affected by other amino acids. Despite this, in the present study, the plasma Trp content in the control and treatment sheep increased at $3 \mathrm{~h}$ after feeding. The increased plasma Trp might be correlated with diet intake.

A marginal increase in the plasma 5-HT level was observed for a long duration in sheep (Fig. 1C). This suggests that 5-HTP administered is metabolized to 5-HT in the intestine or liver by aromatic amino acid decarboxylase, with the resulting product entering the blood circulation. Studies have reported contradicting results with respect to the blood 5-HT level after treatment with 5-HTP. Wa et al. (1995) reported significant increases in urinary 5-HTP and 5-HT excretion, and no significant changes in the blood 5-HT level, whereas, Kaneko et al. (1979) and Takahashi et al. (1976) have reported a significant increase in the blood 5-HT level after the oral administration of 5-HTP. However, there have been a few suggestions regarding a positive relationship between 5-HTP intake and blood 5-HT in ewes.

MLT plasma level was affected by RPT 5-HTP supplementation (111 or $222 \mathrm{mg} / \mathrm{kg} \mathrm{BW}$ ) in sheep (Fig. 1D). We believe that the marked elevation in the plasma MLT level by 5-HTP administration is due to a massaction effect on the 5-HTP-MLT pathway in the pineal gland (Sugden et al., 1985). The three enzymatic reactions decarboxylation, $N$-acetylation, and $O$-methylation do not seem to be saturated during daytime. This is supported by three lines of evidence: 1) an increase in the concentration of 5-HT in the plasma has been observed in sheep treated with RPT 5-HTP (Fig. 1C); 2) monoamine oxidase inhibitors, which elevate 5-HT level, also increase the pineal MLT level in rat (Namboodiri et al., 1983); 3) during daytime, 5-HTP increases the level of pineal gland MLT in rat in vivo (Wurzburger et al., 1976); 4) the treatment with 5-HTP $(200 \mathrm{mg} / \mathrm{kg} \mathrm{BW})$ elevates the pineal 5-HT, $N$-acetylserotonin, and MLT levels in sheep (Sugden et al., 1985). Therefore, the animals receiving RPT 5-HTP presented higher plasma concentrations of MLT during daytime, indicating the transfer of MLT from the pineal gland to the peripheral blood circulation. However, there was no dose-effect relationship between 5-HTP intake and plasma MLT level (Fig. 1D). This might depend on whether there is saturation of the enzyme during the conversion of 5-HTP to MLT, or whether there is also saturation when the synthesized MLT in pineal gland is transported to the blood circulation.

RPT 5-HTP has a significant time effect in regulating plasma 5-HTP, 5-HT and MLT in sheep. The concentration of Trp in the plasma showed negligible change at 1.5-3 $\mathrm{h}$ post feeding. The level of 5-HTP increased initially, and then decreased, whereas, the 5-HT content decreased initially, and then increased, suggesting a contrary tendency with the prolonging of feeding time. The 5-HT level decreased marginally. McKinney et al. (2005) 
revealed that the $K \mathrm{~m}$ value of TPH in sheep is $22 \mu \mathrm{mol} / \mathrm{L}$, and at this point, the tryptophan level in the blood is 38 $\mu \mathrm{mol} / \mathrm{L}$. It is suggested that a part of tryptophan in diet is converted to 5-HTP, which can be converted to 5-HT and MLT. However, there is no obvious change in the content of Trp, 5-HTP, 5-HT, and MLT at 4.5-12 h post feeding, which indicates that the influence of RPT 5-HTP on these components is clearly seen from $0-4.5 \mathrm{~h}$ post feeding.

\section{CONCLUSIONS}

The present study demonstrated that the plasma 5-HTP and MLT concentrations increased at $3 \mathrm{~h}$ post feeding, and then presented a fluctuating trend. Dietary RPT 5-HTP can elevate the plasma 5-HTP, 5-HT, and MLT concentration, but $111 \mathrm{mg} / \mathrm{kg} \mathrm{BW}$ RPT 5-HTP did not increase the plasma 5 -HT concentration. The trend of changes in the plasma 5-HTP level was consistent with that of the plasma 5-HT level when treated with RPT 5-HTP. The plasma Trp level was not affected by RPT 5-HTP.

\section{ACKNOWLEDGEMENTS}

The study was supported by the National Natural Science Foundation of China (grant number 31760681).

Statement of conflict of interest

The authors have declared no conflict of interest.

\section{REFERENCES}

Alonso-Vale, M.I., Andreotti, S., Mukai, P.Y., BorgesSilva, C., Peres, S.B., Cipolla-Neto, J. and Lima, F.B., 2008. Melatonin and the circadian entrainment of metabolic and hormonal activities in primary isolated adipocytes. J. Pineal Res., 45: 422-429. https://doi.org/10.1111/j.1600-079X.2008.00610.x

Arendt, J., 1998. Melatonin and the pineal gland: Influence on mammalian seasonal and circadian physiology. Rev. Reprod., 3: 13-22. https://doi. org/10.1530/revreprod/3.1.13

Birdsall, T.C., 1998. 5-Hydroxytryptophan: A clinicallyeffective serotonin precursor. Altern. Med. Rev., 3 : 271-280.

Broer, S., 2008a. Amino acid transport across mammalian intestinal and renal epithelia. Physiol. Rev., 88: 249-286. https://doi.org/10.1152/ physrev.00018.2006

Broer, S., 2008b. Apical transporters for neutral amino acids: Physiology and pathophysiology. Physiology (Bethesda), 23: 95-103. https://doi.org/10.1152/ physiol.00045.2007

de Farias Tda, S., de Oliveira, A.C., Andreotti, S., do Amaral, F.G., Chimin, P., de Proenca, A.R., Leal, F.L., Sertie, R.A., Campana, A.B., Lopes, A.B., de Souza, A.H., Cipolla-Neto, J. and Lima, F.B., 2015. Pinealectomy interferes with the circadian clock genes expression in white adipose tissue. $J$. Pineal Res., 58: 251-261. https://doi.org/10.1111/ jpi.12211

Dijk, D.J. and Cajochen, C., 1997. Melatonin and the circadian regulation of sleep initiation, consolidation, structure, and the sleep EEG. J. Biol. Rhythms, 12: 627-635. https://doi. org/10.1177/074873049701200618

Ding, K., Wang, H., Xu, J., Li, T., Zhang, L., Ding, Y., Zhu, L., He, J., Zhou, M., 2014. Melatonin stimulates antioxidant enzymes and reduces oxidative stress in experimental traumatic brain injury: The Nrf2ARE signaling pathway as a potential mechanism. Free Radic. Biol. Med., 73: 1-11. https://doi. org/10.1016/j.freeradbiomed.2014.04.031

Enbaek, F. and Magnussen, I., 1978. Determination of 5-hydroxytryptophan in plasma by highperformance liquid chromatography and fluorometric detection after phthaldialdehyde reaction. Clin. Chem., 24: 376-378. https://doi. org/10.1093/clinchem/24.2.376

English, J., Poulton, A.L., Arendt, J. and Symons, A.M., 1986. A comparison of the efficiency of melatonin treatments in advancing oestrus in ewes. J. Reprod. Fertil., 77: 321-327. https://doi.org/10.1530/ jrf.0.0770321

Galano, A., Tan, D.X. and Reiter, R.J., 2011. Melatonin as a natural ally against oxidative stress: a physicochemical examination. J. Pineal Res., 51: 1-16. https://doi.org/10.1111/j.1600079X.2011.00916.x

Galano, A., Tan, D.X. and Reiter, R.J., 2013. On the free radical scavenging activities of melatonin's metabolites, AFMK and AMK. J. Pineal Res., 54: 245-257. https://doi.org/10.1111/jpi.12010

Huether, G., Poeggeler, B., Reimer, A. and George, A., 1992. Effect of tryptophan administration on circulating melatonin levels in chicks and rats: evidence for stimulation of melatonin synthesis and release in the gastrointestinal tract. Life Sci., 51: 945-953. https://doi.org/10.1016/00243205(92)90402-B

Joseph, M.H. and Baker, H.F., 1976. The determination of 5-hydroxytryptophan and its metabolites in 
plasma following administration to man. Clin. Chim. Acta, 72: 125-131. https://doi.org/10.1016/00098981(76)90043-7

Kaneko, M., Kumashiro, H., Takahashi, Y. and Hoshino, Y., 1979. L-5HTP treatment and serum 5-HT level after L-5-HTP loading on depressed patients. Neuropsychobiology, 5: 232-240. https://doi. org/10.1159/000117687

Li, Y., Wang, J., Zhang, Z., Yi, J., He, C., Wang, F., Tian, X., Yang, M., Song, Y., He, P. and Liu, G., 2016. Resveratrol compares with melatonin in improving in vitro porcine oocyte maturation under heat stress. J. Anim. Sci. Biotechnol., 7: 33. https://doi. org/10.1186/s40104-016-0093-9

Magnussen, I., Jensen, T.S., Rand, J.H. and Van Woert, M.H., 1981. Plasma accumulation of metabolism of orally administered single dose L-5-hydroxytryptophan in man. Acta Pharmacol. Toxicol. (Copenh), 49: 184-189. https://doi. org/10.1111/j.1600-0773.1981.tb00890.x

Magnussen, I. and Nielsen-Kudsk, F., 1980. Bioavailability and related pharmacokinetics in man of orally administered L-5-hydroxytryptophan in steady state. Acta Pharmacol. Toxicol. (Copenh), 46: 257-262. https://doi.org/10.1111/j.1600-0773.1980. tb02451.x

Manchester, L.C., Coto-Montes, A., Boga, J.A., Andersen, L.P., Zhou, Z., Galano, A., Vriend, J., Tan, D.X. and Reiter, R.J., 2015. Melatonin: an ancient molecule that makes oxygen metabolically tolerable. J. Pineal Res., 59: 403-419. https://doi. org/10.1111/jpi.12267

Maronde, E. and Stehle, J.H., 2007. The mammalian pineal gland: known facts, unknown facets. Trends Endocrinol. Metab., 18: 142-149. https://doi. org/10.1016/j.tem.2007.03.001

McKinney, J., Knappskog, P.M. and Haavik, J., 2005. Different properties of the central and peripheral forms of human tryptophan hydroxylase. $J$. Neurochem., 92: 311-320. https://doi.org/10.1111/ j.1471-4159.2004.02850.x

Miller, S.C., Pandi-Perumal, S.R., Esquifino, A.I., Cardinali, D.P. and Maestroni, G.J., 2006. The role of melatonin in immuno-enhancement: potential application in cancer. Int. J. exp. Pathol., 87: 81-87. https://doi.org/10.1111/j.0959-9673.2006.00474.x

Mockus, S.M. and Vrana, K.E., 1998. Advances in the molecular characterization of tryptophan hydroxylase. J. mol. Neurosci., 10: 163-179. https:// doi.org/10.1007/BF02761772

Namboodiri, M.A., Sugden, D., Klein, D.C. and Mefford, I.N., 1983. 5-hydroxytryptophan elevates serum melatonin. Science, 221: 659-661. https:// doi.org/10.1126/science.6867734

Pandi-Perumal, S.R., Zisapel, N., Srinivasan, V. and Cardinali, D.P., 2005. Melatonin and sleep in aging population. Exp. Gerontol., 40: 911-925. https:// doi.org/10.1016/j.exger.2005.08.009

Reiter, R.J., Mayo, J.C., Tan, D.X., Sainz, R.M., Alatorre-Jimenez, M. and Qin, L., 2016. Melatonin as an antioxidant: under promises but over delivers. J. Pineal Res., 61: 253-278. https://doi.org/10.1111/ jpi.12360

Sanchez, S., Paredes, S.D., Martin, M.I. and Barriga, C., 2004. Effect of tryptophan administration on circulating levels of melatonin and phagocytic activity. J. appl. Biomed., 2: 169-177. https://doi. org/10.32725/jab.2004.020

Sourkes, T.L., 1987. Aromatic-L-amino acid decarboxylase. Meth. Enzymol., 142: 170-178. https://doi.org/10.1016/S0076-6879(87)42026-0

Sugden, D., 1989. Melatonin biosynthesis in the mammalian pineal gland. Experientia, 45: 922-932. https://doi.org/10.1007/BF01953049

Sugden, D., Namboodiri, M.A., Klein, D.C., Grady, R.K., Jr. and Mefford, I.N., 1985. Ovine pineal indoles: effects of L-tryptophan or L-5-hydroxytryptophan administration. J. Neurochem., 44: 769-772. https:// doi.org/10.1111/j.1471-4159.1985.tb12881.x

Takahashi, S., Takahashi, R., Masumura, I. and Miike, A., 1976. Measurement of 5-hydroxyindole compounds during L-5-HTP treatment in depressed patients. Folia Psychiatr. Neurol. Jpn., 30: 463473. https://doi.org/10.1111/j.1440-1819.1976. tb02669.x

Vriend, J. and Reiter, R.J., 2015. Melatonin feedback on clock genes: A theory involving the proteasome. J. Pineal. Res., 58: 1-11. https://doi.org/10.1111/ jpi.12189

Wa, T.C., Burns, N.J., Williams, B.C., Freestone, S. and Lee, M.R., 1995. Blood and urine 5-hydroxytryptophan and 5-hydroxytryptamine levels after administration of two 5-hydroxytryptamine precursors in normal man. Br. J. clin. Pharmacol., 39: 327-329. https://doi. org/10.1111/j.1365-2125.1995.tb04456.x

Wang, F., Tian, X., Zhang, L., Gao, C., He, C., Fu, Y., Ji, P., Li, Y., Li, N., Liu, G., 2014. Beneficial effects of melatonin on in vitro bovine embryonic development are mediated by melatonin receptor 1 . J. Pineal Res., 56: 333-342. https://doi.org/10.1111/ jpi.12126

Westenberg, H.G., Gerritsen, T.W., Meijer, B.A. and van Praag, H.M., 1982. Kinetics of 1-5- 
hydroxytryptophan in healthy subjects. Psychiat. Res., 7: 373-385. https://doi.org/10.1016/01651781(82)90074-9

Wurzburger, R.J., Kawashima, K., Miller, R.L. and Spector, S., 1976. Determination of rat pineal gland melatonin content by a radioimmunoassay. Life Sci., 18: 867-877. https://doi.org/10.1016/00243205(76)90014-X

Zhdanova, I.V., 2005. Melatonin as a hypnotic: Pro. Sleep Med. Rev., 9: 51-65. https://doi.org/10.1016/j. smrv.2004.04.003 